\title{
Measurement and Analysis of Axial End Forces in a Full-Length Prototype of LHC Main Dipole Magnets
}

\author{
K.Artoos, T.Kurtyka, F.Savary, R. Valbuena, J. Vlogaert \\ CERN, Geneva, Switzerland
}

\begin{abstract}
A full-length, twin aperture prototype (MBP2N1) dipole magnet for the LHC project was assembled at CERN with collared coils delivered by industry. The design of this prototype is close to that foreseen for the dipole series manufacture as far the coil geometry and that of the yoke components are concerned.

The bolts that transfer the axial magnetic forces from the coll ends to the cold mass end plates were instrumented to verify the axial coil support. These axial forces were initially measured after partial assembly, during a standard and an accelerated cool down Introduction to $1,9 \mathrm{~K}$, and during magnet excitation up to $9.2 \mathrm{~T}$. High force levels were observed, triggering a comparison with analy ticaI models and measurements routinely made on $1-\mathrm{m}$ single aperture dipole models. The prototype magnet was re-assembled with lower initial axial force settings and with additional instrumentation, to monitor these forces during the entire assembly process, and re-tested, to possibly correlate axial forces with training behaviour. This paper reports about the experimental observations and provides models towards their understanding.
\end{abstract}

\section{INTROCUTION}

Some of the mechanical instrumentation used in the LHC dipole short model program [1], [2], [3] was introduced in a fill length LHC twin-aperture prototype (MBP2N1). Companion papers at this conference [4], [5] describe its design, close to the series manufacture design.

- The axial forces on the coil ends, which are retained by the magnet end plates, were measured for the first time on a dipole prototype during assembly, cool down and excitation. An initial axial pre-load (MBP2NI.V1) was chosen to ensure a correct contact between coil ends and end plates at $1.8 \mathrm{~K}$. The magnet was cooled down with a standard cool down rate ("slow" cool down) and with an accelerated one ("fast" cool down). An accelerated cool down can reduce the time needed for the reception tests of the magnets and for LHC commissioning and operation. The transient thermal axjal forces that can occur during such a fast cool down had to be verified.

During excitation, the increase of axial forces on the ends was measured and the distribution of axial electromagnetic forces between the magnet components was estimated.

After a first test run, the magnet was reassembled with a lower axial pre-load (MBP2N1.V2), and tested again.

Manuscript received on 27 September 1999

\section{INSTRUMENTATJON}

Eight bolts, instrumented as axial compression load cells, apply a load between' the $50-\mathrm{mm}$ thick end plate and the magnet coil ends (two bolts per end and per aperture - see Fig. 1). Each load cell consists of four strain gauges in a sixwire full bridge configuration. The gauges are compensated for temperature and magnetic field, and are positioned in such a way that there is almost no influence from bending and edge effects. Each load cell is calibrated for force and temperature. The absolute error of the load cell at $1.8 \mathrm{~K}$ should be smaller than $10 \%$ [6]

Appropriate strain gauges were added during the reassembly of the nagnet to monitor the strain created by the weld of the magnet end covers, the strain in the magnet end plates and the distribution of the longitudinal strain in the shrinking cylinder.

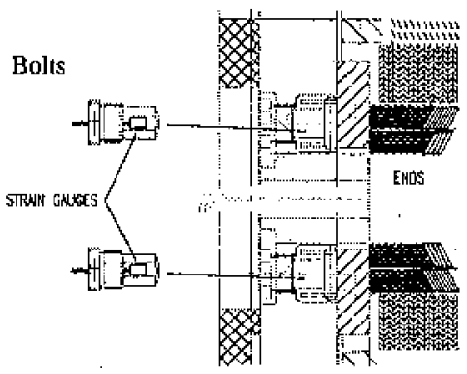

Fug.1. The bolts apply a force on the coil ends

Resistance temperature sensors measured the temperature distribution of the magnet during the thermal cycles. The temperature gauges of the cold mass were positioned on the outside of the shrinking cylinder at the two extremities and at the middle of the magnet.

\section{MEASUREMENTS AND DISCUSSION OF RESULTS}

\section{A. Assembly and Re-Assembly}

After partial assembly of the cold mass, the load cell bolts were tightened with a torque key, applying an axial pre-load to the coil ends. A high increase of bolt forces was observed after the welding of the magnet end covers to the cold mass. This increase was confirmed and explained with additional strain gauges during the disassembly and re-assembly of the magnet end covers for MBP2N1.V2. The shrinkage of the citcular weld that attaches the end covers to the cold mass (see Fig. 2) 
created a bending moment to the end plate, balanced by an increase of the bolt forces. Residual strain levels on the stainless steel shrinking cylinder in the zone between end plate and end cover weld were measured as high as $800 \mu \mathrm{m} / \mathrm{m}$ and geometrical measurements indicated plastic deformation of the cylinder.

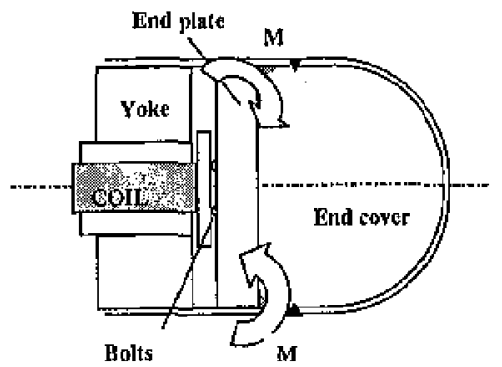

Fig.2. Bending of the end plate created by welding

TABLE I BOLT FORCES ASSEMPLY, FORCEENDAAPERTLRE (A) Pre-load force

End covers $(\mathrm{kN})$

\begin{tabular}{lllll}
\hline MBP2N1 & A1 & A2 & A1 & A2 \\
\hline V1 CS & 56 & 57 & 82 & 85 \\
NCS & 56 & 56 & 96 & 17 \\
\hline V2 CS & 11 & 11 & 18 & 33 \\
NCS & 10 & 10 & 43 & 47 \\
\hline
\end{tabular}

Connection (CS) and Non Connection Side (NCS)

The pre-load of the bolts was lowered for the re-assembly. This resulted however in a highar spread of forces between the bolts after welding (see Table I).

\section{B. Thermal Cycles}

1) First part of the cool down $(300 \mathrm{~K}$ to $80 \mathrm{~K}$ ): During a cool down to $80 \mathrm{~K}$, gaseous helium with decreasing temperature for a standard ("slow") cool down (cool down rate 1 to $0.14 \mathrm{~K} / \mathrm{min}$ ) and helium at $80 \mathrm{~K}$ for an accelerated cool down $(9 \mathrm{~K} / \mathrm{min}$ at $\mathrm{CS})$, is injected from the connection side.

TABLE II

AXIAL END FORCES (KN)/AFERTRREAT $295 \mathrm{~K}$ AND $1.8 \mathrm{~K}$ FOR SLOW AND FAST CGOL DOWN

\begin{tabular}{|c|c|c|c|c|c|}
\hline & MBP2N1 & \multicolumn{2}{|c|}{$295 \mathrm{~K}$} & \multicolumn{2}{|c|}{$1.8 \mathrm{~K}$} \\
\hline \multirow{2}{*}{$\frac{3}{\square}$} & $\mathrm{V} 1 \mathrm{CS}$ & \multicolumn{2}{|c|}{82} & \multicolumn{2}{|c|}{100} \\
\hline & V1 NCS & \multicolumn{2}{|c|}{95} & \multicolumn{2}{|c|}{118} \\
\hline \multirow{2}{*}{ 惫 } & $\mathrm{V} 1 \mathrm{CS}$ & \multicolumn{2}{|c|}{95} & \multicolumn{2}{|c|}{117} \\
\hline & V1 NCS & \multicolumn{2}{|c|}{88} & \multicolumn{2}{|c|}{117} \\
\hline \multirow{2}{*}{$\frac{z}{n}$} & $\mathrm{~V} 2 \mathrm{CS}$ & A1 16 & A2 36 & A1 15 & A2 55 \\
\hline & $\mathrm{V} 2 \mathrm{NCS}$ & A1 41 & A2 45 & A1 70 & A2 61 \\
\hline
\end{tabular}

\footnotetext{
1) Not measured
}

A small tratsient increase of axial force was measured at the connection side during the start of the slow cool down. After this, the forces increased more gradually (Fig.3).

During the accelerated ("fast") cool down ( $9 \mathrm{~K} / \mathrm{min}$ at $\mathrm{CS}$ ) the axial forces at the connection side increased rapidly (Fig. 4) to a maximum of $190 \mathrm{kN} / \mathrm{end} / \mathrm{aperture} \mathrm{(Fig.} \mathrm{4).}$

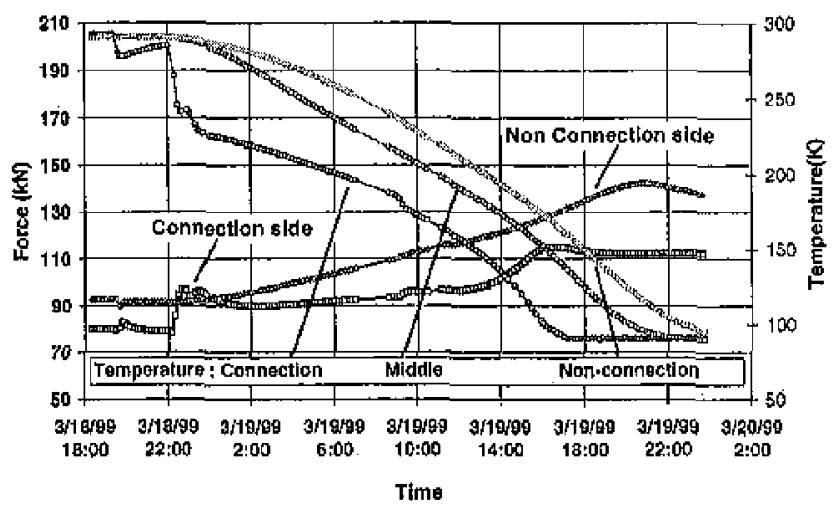

Fig. 3. MBP2N1.V1 Slow cool down, force/aperture

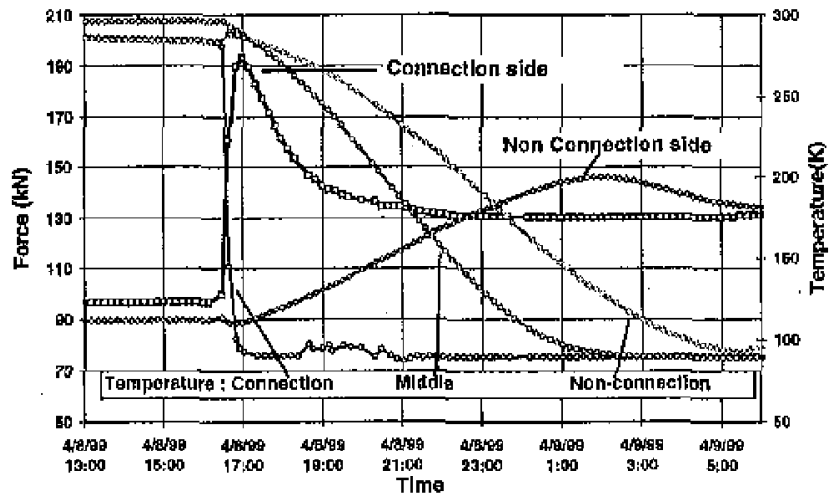

Fig.4. MAP2N1.V1 Fast cool down, force/apertare

This transtent increase of bolt forces at the beginning of a cool down can be explained by high thermal gradients and thermal deformation of the connection side of the magnet, thermally shocked by the injection of cold helium, A model [7] predicted the increase of bolt forces created by local conical deformation of the shrinking cylinder and thermal deformation of the end plate (see Fig. 5). 


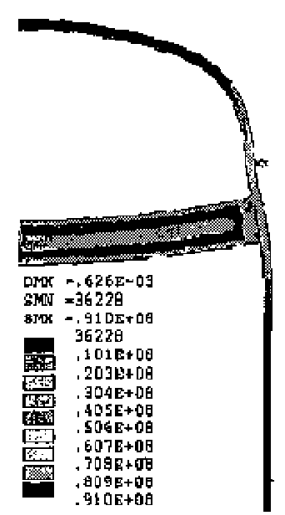

Fig.5. Transient thernal deformation of the end plate

2) Second part of the cool down ( $80 \mathrm{~K}-4.2 \mathrm{~K}$ ): During the second part of the cool down, heljum at $4.2 \mathrm{~K}$ is injected into the cold mass. A small initial, transient increase in bolt force was followed by a decrease of about $20 \mathrm{kN} /$ aperture on both connection and non-connection side. This decrease towards the end of a cool down needs further analysis and might be related to a decrease of the mating force between the collars and the stainless steel part of the yoke laminations at the end of the cool down.

After the completed cool down, there was a nel increase of bolt forces. A summary of the force values before and after cool down is given in Table II.

\section{During Powering of the Magnet}

During excitation, the load cells registered the part of the axial electromagnetic force transferred to the magnet end plate. The increase of bolt force was linear with current squared. For MBP2N1.V2, the bolt forces were not well distributed after assembly between the two apertures at the connection side. Aperture A1 transferred less force to the end plate during excitation (see Tables III and IV).

TABLE III

JNCRGASE OF AXIAL END FORCES IN KN/KA'A/APERTURE ("TYPICAL 1-METRE MODEL, 7O MM END PLATE, 6.BLOCK COIL)

\begin{tabular}{llllll}
\hline \multicolumn{2}{l}{ MBP2N1.V1 } & \multicolumn{2}{l}{ MBP2N1.V2 } & \multicolumn{2}{l}{ 1-metre model * } \\
\hline CS & NCS & CS & NCS & CS & NCS \\
\hline 0.64 & 0.67 & $0.09(\mathrm{~A} 1)$ & 0.62 & 0.36 & 0.42 \\
& & $0.63(\mathrm{~A} 2)$ & & & \\
\hline
\end{tabular}

TABLE IV

ABSOL UTE AXIAL END FORCES PEACHED AT NOMIMAL FIELD (KN/APEKTURE)

\begin{tabular}{cccccc}
\hline \multicolumn{2}{l}{ MBP2N1 V1 } & \multicolumn{2}{c}{ MBP2N1 V2 } & \multicolumn{2}{c}{1 -metre model * } \\
\hline CS & NCS & CS & NCS & CS & NCS \\
\hline 198 & 207 & $\begin{array}{c}25(\mathrm{~A} 1) \\
150(\mathrm{~A} 2)\end{array}$ & 155 & $60-90$ & $60-90$ \\
& & & & \\
\hline
\end{tabular}

The axial strain in the shrinking cylinder was measured witl eight strain gauges distributed over half of the length of MBP2N1.V2 (see Fig. 8)

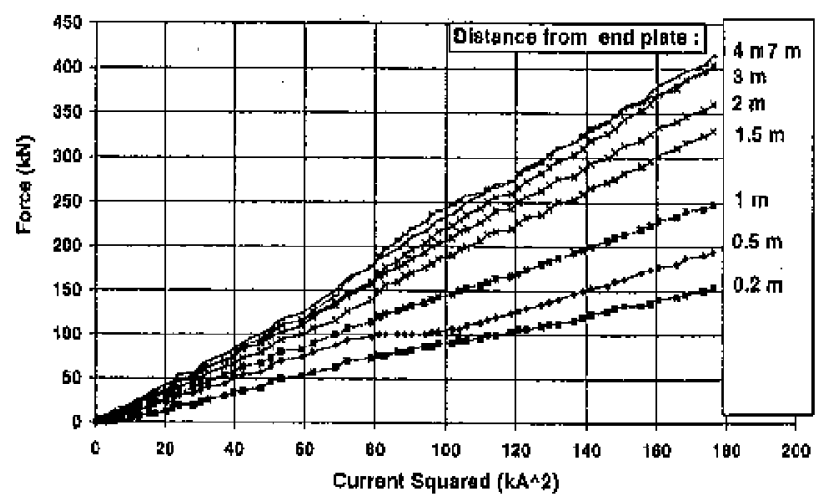

Fig.6. Axial strain in the shrinking oylinder

The axial electromagnetic forces will create an elongation of the coil that is retained by the bolts and by the friction betweer the coils, collar and yoke laminations. From the measurements it shows that the part of the electromagnetic force that is transferred to the shrinking cylinder develops over the first twc metres from the ends. The measured strain at the middle of the magnet corresponds to about $93 \%$ of the axial electromagnetic forces being supported by the shrirking cylinder and $7 \%$ by the coil and other structures like collaring rods (for $375 \mathrm{kN}$ electromagnetic force calculated at nominal fjeld [i]). The mentioned force in the cylinder was however calculated by considering the axial rigidity of the shrinking cylinder only The combined stiffness of cylinder and yoke laminations mas be higher.

\section{Evolution of the End Forces}

The axial end forces per aperture of MBP2N1.V1 at differen moments during the testing are shown in figure 7 . The increase of 25-35 kN per aperture after the welding of the end covers is shown again. There was a net increase of the bolt forces of $20 \mathrm{kN}$ per aperture after a standard cool down and $30 \mathrm{kN}$ pel aperture at the connection side after an accelerated cool down.

The forces measured at zero current were quite stable during the current cycles and throughout the first 14 quenches. The increased $9 \mathrm{kN} / \mathrm{aperture}$ at the connection side anc $7 \mathrm{kN} / a p e r t u r e$ at the non-connection side. There was hence some ratcheting (or build up of axial pre-load). 


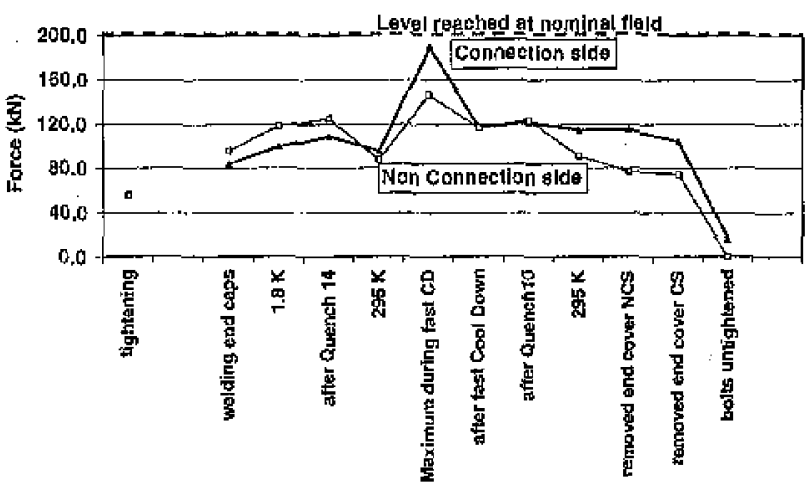

Fig.7. Variation of boll forces at different stages (kN/aperture)

After the first warm-up, the forces reached the same level as before the first cool down. However, after the accelerated cool down, the forces at the connection side increased by $9 \mathrm{kN} /$ aperture. After the second warm-up, the forces at the contrection side were higher than before the first cool down. This indicates that some irreversible movements took place during the accelerated cool down.

The welds that attached the magnet end covers to the magnet cold mass were cut during the magnet disassembly.

The elastic part of the conical deformation of the shrinking cylinger was released during this operation and the axial forces on the coil ends were reduced by $14 \mathrm{kN} / a p e r t u r e$ at the connection- and $11 \mathrm{kN} /$ aperture at the non-connection side. $A$ part of the conical deformation was found to be permanent. The measurement of the untightened bolts revealed that sonc of the bolts at the connection side had a sniall zero offset because of plastification. The instrumentation was not foreseen for the very high forces reached during the accelerated cool down.

The influence of the axial end forces on the training behaviour is not yet clear. All quenches but two were in the coil ends, most likely however because of a lack of azimuthal pre-stress in the coil ends [5]. The !evel of end forces reached was much higher than that of the forces usually measured in 1-m single aperture dipole models. Some short models were tested with higher initial axial pre-load, but there was no clear effect on the training behaviour [9].

Before the fast cool down, all training quenches were at the non-connection side. After the accelerated cool down, training quenches moved to the connection side end, the side where the helium is injected and where the high transient thermal forces were measured. More testing and analysis is needed to confirm the observed behaviour.

The training behaviour of MBP2N1.V2, reassembled with a reduced axial pre-load (see Table $\mathrm{D}$ ), was not very different from that observed lor MBP2N1.V1. Because of the lower initial values, the bolt forces reached at nominal field were however $25 \%$ lower, More tosts are needed to confirm any influence of the Force level at the axial bolts on magnet training.

\section{CONClusions}

The mechanical measurements introduced in the full-length LHC twin-aperture protolype (MBP2N1) dipole magnet were found to be very useful. The load cells on the end bolts have shown a significant increase of axial force on the coil ends after the welding of the magnet end covers. A net increase of bolt forces was also measured after cool down. The initial axial preload was lowered during a subsequent to-assembly, still guaranteeing a good axial coil support at $1.8 \mathrm{~K}$.

The measuroments made during excitation and from quench to quench gave more information about the participation of the different magnet components in retaining the axial electromagnetic forces. The axial electromagnetic forces are almost completely transferred, over the first $2 \mathrm{~m}$ from the magnet ends, to the shrinking cylinder. The end bolts transfer about $45 \%$ of the load to the end plates and from there to the shrinking cylinder. The remaining $55 \%$ appear to be taken by friction between coils, collars and yoke laminations.

The influence on the magnet training behaviour of the transient thermal end forces during an accelerated cool down is not clear. More tests have to be performed and the next prototypes will again be cquipped with axial load cells.

\section{ACKNOWLEDGMENTS}

The authots wish to express their thanks to L. Evans, D.Güsewell, Ph. Lebrun and C. Wyss for their support to the mechanical measurements. Our thanks are also due to the team that prepared the instrumentation, to the team of the CERN LHC magnet assembly facility, to the team responsible for the cold tests and to the team responsible for the data acquisilion and archiving.

\section{REFERENCES}

[1] N.Ardreev et al. : "Mechanical behaviour of the short madels of LHC main dipole magnets", MT-15 1997, Bejijing. China

[2] N.Andreev et al. :"The 1-m long single aperture dipole coil test progran for LHC", EPAC 1996 Sitges, Spain

[3] N.Andreev et al. : "State of the short dipole nodel program for the LHC", EPAC 1998, Stockholm, Sweden

[4] P.Fessia et al. : "Selection of the cross-section design for the LHC main dipole", this conference MT16, 1999, Florida, USA

[5] K.Artoos et al, :"Design, manufacturing status, fitst results of the LHC main dipole final prototypes and steps towards series manufacture", this conference MT 16 1999, Florida, USA

[6] K.Artoos.et al. : "Performance of strain gauges in superfllid heliujn", CERN EST-ESI/97-1 Techtical note 1997, Geneva, Switzerland

[7] P.Cupial et al. : "Finite element analysis of the influence of accelerated cool down on the mechanical behaviour of 15 m long dipolo magnets" CERN EST-ESL99. Technical note 1999, Geneva, Switzerland, to be published

[8] S. Russenschuck Private communication and CE[RN Yellow Repont 99-01

[9] K.Artoos et al. : "Stntus of the short dipole model progratn for the LHC", this conference MT 16 1999, Florida, USA 